\title{
O LÚDICO COMO ALIADO NA ALFABETIZAÇÃO E LETRAMENTO
}

\section{ARTIGO ORIGINAL}

LIMA, Adimilson Ferreira ${ }^{1}$

JUNIOR, Adival José Reinert ${ }^{2}$

LIMA, Adimilson Ferreira. JUNIOR, Adival José Reinert. O lúdico como aliado na alfabetização e letramento. Revista Científica Multidisciplinar Núcleo do Conhecimento. Ano 05, Ed. 03, Vol. 08, pp. 05-13. Março de 2020. ISSN: 2448-0959, Link de acesso: https://www.nucleodoconhecimento.com.br/pedagogia/ludico-comoaliado

\section{RESUMO}

Este trabalho de revisão bibliográfica objetiva verificar a importância do lúdico como um aliado do profissional de educação, e, a partir da temática, tem-se como intuito refletir sobre os instrumentos e métodos metodológicos voltados aos processos de alfabetização e letramento do público infantil. Considerando as teorias direcionadas as ideias de leitura, e, também, de escrita, podemos entender que essas têm sido somadas aos conceitos de alfabetização e letramento. A alfabetização diz respeito ao processo de aprendizagem do público infantil, sobretudo de absorção do alfabeto, uma vez que ele é um código acionado para se comunicar via escrita. Já o letramento, por conseguinte, refere-se aos exercícios que colocam o aprendiz em contato tanto com a leitura quanto com a escrita por intermédio do acionamento de técnicas que fazem com que esse aprendiz interaja nos mais diversos contextos sociais. O lúdico, nessa relação, revela-se como um instrumento essencial, pois ajuda a despertar, na

\footnotetext{
${ }^{1}$ Graduação e Pós-Graduação em Pedagogia.

2 Especialização em Teoria Psicanalítica. Especialização em Orientação, Supervisão e Gestão Escolar Democrática. Especialização em Docência do Ensino Fundamental, Médio e Superior. Graduação em Matemática.
} 
criança, a curiosidade e o prazer no processo educacional. Nesse contexto, a pesquisa reitera que exercícios lúdicos são indispensáveis para fomentar as práticas que envolvem a leitura e a escrita, pois são verdadeiros facilitadoras dos relacionamentos e das vivências no contexto escolar.

Palavras-chave: Educação, alfabetização, letramento, lúdico, aprendizagem.

\section{INTRODUÇÃO}

Este artigo objetiva refletir sobre o papel das atividades lúdicas no processos que englobam tanto a alfabetização quanto o letramento do público infantil. A escolha do tema é importante e relevante se considerada a importância do brincar no desenvolvimento psicomotor, já que estudos atuais tem demonstrado que existe uma dupla ação nesse processo: o caráter preventivo e terapêutico. Assim sendo, a ação psicomotora diz respeito à atuação, a partir do corpo, do psiquismo, sobretudo das funções instrumentais que faz com que um indivíduo se adapte ao meio. Assim, a tríade: brincar, aprendizagem e psicomotricidade deve ser pensada, pois é indispensável na formação da criança, uma vez que favorece a absorção de conteúdos e o desenvolvimento de habilidades diversas, promovendo, então, a imaginação, e, principalmente, as transformações de sujeito em relação ao seu objeto de aprendizagem, e, também, o desenvolvimento motor, psicológico e afetivo da criança.

Compreende-se, então, que os exercícios lúdicos são capazes de fomentar o desenvolvimento de aptidões diversas, e, também, o ajuste do comportamento psicomotor. A escolha do tema em comento deu-se frente aos índices de analfabetismo que assolam o país, trazendo uma inquietação sobre a importância de se tratar sobre conceitos de alfabetização e letramento, verificando-se a importância de ter, em sala de aula, métodos lúdicos que possam favorecer o ensino e a aprendizagem. Então, a questão é: por qual razão as atividades lúdicas não têm sido propostas para alfabetizar letrando? Como profissionais da educação, pode-se afirmar que a formação do professor se volta para uma escola ideal. Formam-se com a ideia errônea de que todas as crianças aprendem no mesmo ritmo e que não possuem 
problemas de relacionamento. Parte-se da hipótese de que aprender sem um propósito os conteúdos diversos a partir da leitura e escrita não é suficiente para sanar os problemas do cotidiano. Isso mostra que o trabalho do professor nunca está pronto, tem que estar em constante evolução.

\section{LETRAMENTO: DADOS HISTÓRICOS}

A ideia de letramento tem sido, atualmente, mais difundida do que a algum tempo atrás. Sabe-se que o termo foi empregado, primeiramente, por Mary Kato em seu livro intitulado de "No mundo da escrita", publicado em 1986. Fora a mesma autora que, em 1995, retomou o conceito em outro livro titulado "Alfabetização e Letramento", dando margens para que Ângela Kleiman passasse a valer-se do termo letramento, lançando, também, um livro em 1995 intitulado de "Os significados do letramento". O termo letramento surgiu devido à necessidade de nomear uma nova situação que fosse capaz de auferir leitura e, também, a escrita, em um exercício pedagógico desapegado dos moldes tradicionais de ensino-aprendizagem, o que implica na adesão a métodos e instrumentos mais atentos ao contexto atual do ensino, isto é, precisava-se desapegar de tendências até então habituais do ler e escrever, calcadas na aprendizagem voltada, apenas, à codificação e decodificação do sistema de escrita (SOARES, 2004).

Nesse contexto, torna-se válido reiterar, com base nos fatos aqui expostos, que a necessidade de utilizar esse novo conceito com um significado mais amplo do que o atribuído à alfabetização ocorreu, simultaneamente, no Brasil, e, ainda, em outros países da Europa e, também, da América do Norte, apesar de que, os Estados Unidos e Inglaterra, como ressaltado por alguns estudos, já tinham conhecimento sobre a palavra letramento (SOARES, 2004). Assim sendo, deve-se compreender que o termo letramento, contudo, não se encontra dicionarizado, porém, uma ideia sobre o que é, de fato, esse processo, pode ser encontrada no Dicionário Contemporâneo da Língua Portuguesas de Caldas Aulete escrito no século passado, sendo o termo, então, considerado sinônimo de "escrita" e substantivo do verbo letrar com a definição de "soletrar". 


\subsection{COMO O LETRAMENTO TEM SIDO PENSADO ATUALMENTE?}

Após a compreensão de que far-se-ia necessário atribuir um novo conceito à alfabetização, ou seja, às técnicas de leitura, e, também, de escrita, ampliou-se o conceito atribuído ao que hoje chamamos de letramento. Letramento é o termo atribuído àqueles que não apenas sabem ler e escrever, mas também cultivam e praticam práticas sociais por meio de um processo construído na comunidade, em que um molda o outro. Nessa esfera, entendemos que os exercícios voltados ao ensinoaprendizagem pautados no contato com a leitura e a escrita são fundamentais para que os alunos consigam interagir por meio da linguagem nas mais diversas situações do cotidiano. Assim sendo, constrói-se uma nova visão de alfabetização. Soares (2006, p. 25) assim compreende o letramento:

Seu significado atual, veio da versão inglesa da palavra "literacy", originária do latim "littera" (letra), com o sufixo "cy", que denota qualidade, condição, estado, fato de ser Portanto, letramento é o resultado da ação de "letrar-se" é a ação de ensinar e aprender as práticas da leitura e escrita. É o estado ou condição que adquire um grupo social ou um indivíduo como consequência de ter-se apropriado da escrita e de suas práticas sociais.

Assim sendo, torna-se essencial entender que o letramento compreende muito mais do que atividades de leitura e escrita, ou seja, é necessário propor exercícios que, de alguma forma, evidenciam o uso ativo das técnicas de leitura e escrita para construir práticas sociais, por meio do uso da linguagem, acionando, portanto, habilidades úteis.

\subsection{ALFABETIZAÇÃO X LETRAMENTO}

Alfabetizar significa ensinar o alfabeto a fim de proporcionar, à criança (ou adulto), a utilização deste como um código de comunicação. A alfabetização é uma das primeiras estratégias para colocar o aprendiz em contato com os bens culturais mais diversos. Nos anos 70 boa parte da sociedade brasileira era analfabeta, e, assim, havia pouca prática de leitura e escrita. Por isso, a alfabetização era compreendida 
como uma mera sistemática de ensino simples que, na época, parecia ser suficiente para considerar um cidadão alfabetizado. Muitas mudanças ocorreram na sociedade, e, com o término do século anterior, um grande desafio foi alcançado: a redução do analfabetismo.

Porém, é de igual relevância ressaltar que, tratando-se do Brasil, algumas práticas, até algum tempo atrás, enfatizavam que o aprendiz estava, de fato, alfabetizado, quando esse, por exemplo, conseguia localizar e compreender as informações materializadas em formatos textuais diferenciados, todavia, em outros contextos, saber assinar o nome significava estar alfabetizado. Pelo exposto, torna-se evidente a necessidade de uma mudança no processo de ensino/aprendizagem por meio do letramento pois, assim, evita-se ideias ultrapassadas e conservadoras acerca da alfabetização de uma criança, que consistia em, apenas, decorar o código, sendo incapaz de compreender e interpretar o sentido dos textos.

O professor deve tomar alguns cuidados para envolver o aluno no processo de construção da escrita, tais como criar um ambiente letrado, em que a leitura e a escrita estejam presentes mesmo antes que a criança saiba ler e escrever convencionalmente; considerar o conhecimento prévio das crianças, pois, embora pequenas, elas levam para a escola o conhecimento que advém da vida; participar com as crianças de práticas de letramento, ou seja, ler e escrever com função social; utilizar textos significativos, pois é mais interessante interagir com a escrita que possui um sentido, constitui um desafio e dá prazer; utilizar textos reais, que circulam na sociedade, e utilizar a leitura e a escrita como forma de interação, por exemplo, para informar, convencer, solicitar ou emocionar (BRASIL, 1998, p. 38).

Quando se reflete sobre o letramento, deve-se manter em mente que os alunos dificilmente aprenderão, efetivamente, se, a eles, forem propostos exercícios repetitivos e pouco interessantes, e, dessa forma, o foco deve estar voltado à absorção do conhecimento sobre escrita. Nesse contexto, as teorias sobre a prática do letramento não se voltam, apenas, aos alfabetizados De acordo com Vygotsky 
(1984), o letramento é um processo histórico, e, como tal, modifica-se conforme os instrumentos e métodos pedagógicos voltados ao letrar são transformados ao longo da história. Tem sido compreendido como uma maneira mais sofisticada do comportamento humano que engloba aspectos como: memória ativa, resolução de problemas, raciocínio abstrato, etc. Assim sendo, é importante que fique claro que a fase da escolarização é apenas um dos vértices do letramento, visto que o caráter dinâmico do conhecimento pressupõe práticas nos diversos contextos.

\subsection{ALFABETIZAR LETRANDO: UM DESAFIO NECESSÁRIO}

Soares apud Ribeiro (2003, p. 91) frisa, em seu estudo, que as técnicas de alfabetização, e, também, de letramento, influenciam, diretamente, no domínio do sistema de escrita:

Alfabetizar é o processo pelo qual se adquire o domínio um código e das habilidades de utilizá-lo para ler e escrever, ou seja: o domínio da tecnologia - do conjunto de técnicas - para exercer a arte e ciência da escrita. Ao exercício efetivo e competente da tecnologia da escrita denomina-se Letramento que implica habilidades várias, tais como: capacidade de ler ou escrever para atingir diferentes objetivos.

O domínio da escrita é essencial pois ela assegura, ao aluno, um contato mais amplo e diversificado dele com o mundo a sua volta, isto é, permite que ele o conheça de uma forma única e de grande valia para as suas percepções e aprendizagem. Em função disso Leite (2001, p. 25) afiança que:

Talvez a diretriz pedagógica mais importante no trabalho (... dos professores), tanto na pré-escola quanto no ensino médio, seja a utilização da escrita verdadeira nas diversas atividades pedagógicas, isto é a utilização da escrita, em sala, correspondendo às formas pelas quais ela é utilizada verdadeiramente nas práticas sociais. Nesta perspectiva, assume-se que o ponto de partida e de chegada do processo de alfabetização escolar é o texto: trecho falado ou escrito, 
caracterizado pela unidade de sentido que se estabelece numa determinada situação discursiva.

A dissociação de ambos no processo educacional é um erro, como aponta Soares (2004, p. 14):

Dissociar alfabetização e letramento é um equívoco porque, no quadro das atuais concepções psicológicas, linguísticas e psicolinguísticas de leitura e escrita, a entrada da criança (e também do adulto analfabeto) no mundo da escrita ocorre simultaneamente por esses dois processos: pela aquisição do sistema convencional de escrita - a alfabetização - e pelo desenvolvimento de habilidades de uso desse sistema em atividades de leitura e escrita, nas práticas sociais que envolvem a língua escrita - o letramento.

Ferreiro (2004) defende que a criança, em seu processo de alfabetização, necessita, além da maturação, estar envolvida no processo da escrita e leitura, ou seja, desejar já ter adquirido muitas informações sobre a grafia e leitura dos textos em rótulos, propagandas, etc. Desse modo, a criança constrói o sistema de escrita, inventando letras, as maneiras de combiná-las e atribuindo significado ao que se escreve. Cabe, à escola, fornecer, às crianças, espaço e tempo para que esses aprendizes construam a sua própria ideia de leitura e escrita, e, para isso, o professor, aproveitando os jogos, terá condições de, em seu planejamento semanal, selecionar atividades que tenham real significado.

\subsection{DIFERENÇAS ENTRE JOGAR E BRINCAR}

Lúdico significa "ludus", isto é, jogo ou brincadeira (HUIZINGA, 2014). Barreto (2012, p. 32) compreende a brincadeira como uma "atividade lúdica livre, separada, incerta, improdutiva, governada por regras e caracterizada pelo faz de conta". Para o autor, essa atividade ocorre dentro dos limites de tempo e espaço da criança. Para Sá (2015) a brincadeira está relacionada à vida de toda criança e ocorre no tempo e espaço desta, envolvendo aspectos que estão ao seu redor e no seu interior, de maneira 
individualizada ou combinada. Silva (2013), em seu estudo, compreende o ato de brincar como uma distração, e, assim, é capaz de fazer com que a criança descarregue sua energia. Brougère (2001, p. 99), em sua pesquisa, alude que "brincadeira é uma mutação do sentido, da realidade: as coisas tornam-se outras. É um espaço à margem da vida comum, que obedece a regras criadas pelas circunstâncias". Kishimoto (2016, p. 110) complementa afirmando que:

Brincando as crianças aprendem a cooperar com os companheiros, a obedecer às regras do jogo, a respeitar os direitos dos outros, a acatar a autoridade, a assumir responsabilidades, a aceitar penalidades que the são impostas, a dar oportunidade aos demais, enfim, a viver em sociedade.

Portanto, a brincadeira infantil pode ser compreendida como uma atividade que envolve os sentidos, e, assim, faz com que a criança sinta sensações únicas no seu mundo, tornando-o real, pois, para ela, há um significado próprio. É, desse modo, a forma como se organizam, inventam, conversam, criam papéis, transformam os cenários, imaginam etc, enfim, trata-se de um mundo repleto de sentimentos e expressividades. É na brincadeira que a criança desenvolve as competências motora, mental, social e criativa. Deve-se ressaltar, também, que é uma atividade de caráter intrinsecamente humano, e, em razão disso, trata-se de uma forma de expressão típica da infância. O jogo, segundo Huizinga (1980, p. 33), é uma:

(...) atividade voluntária exercida dentro de certos e determinados limites de tempo e espaço, segundo regras livremente consentidas, mas absolutamente obrigatórias, dotado de um fim em si mesmo, acompanhado de um sentimento de tensão e alegria e de uma consciência de ser diferente de vida cotidiana.

Acredita-se que alguns jogos são desprovidos de organização, contudo, generalizar este critério, ao analisar as contribuições teóricas de muitos especialistas, seria alarmante. (BENJAMIN, 2009). Ainda assim, umas das características básicas do jogo é a liberação de conflitos, sendo que, neste critério, o que se busca valorizar é a 
função educacional da atividade lúdica. De fato, o jogo tem um papel fundamental na liberação do eu por uma solução de compensação ou liquidação de conflitos (CHATEAU, 2007). Entendemos que os jogos implicam no seguimento de regras direcionadas de maneira correta, proporcionando entretenimento coletivo, além de contribuir para a compreensão da cooperação, vitória, derrota e equilíbrio entre os participantes.

\section{A EDUCAÇÃO INFANTIL NA ATUALIDADE}

Devemos, neste estudo, enfatizar que a Lei de Diretrizes e Bases da Educação Nacional, também conhecida como LDB, determinou, em 1996, a priorização da educação de alunos com idade de zero a seis anos. Destarte, a legislação incluiu a Educação Infantil na educação básica. Com tal delegação, os municípios passaram a ser responsabilizados pelo gerenciamento da educação infantil, e, assim, possuem uma missão: devem fomentar uma educação de qualidade e ela é obrigatória para todos. Por isso Barbosa Magalhães (2011) defende que a Educação Infantil na década de 1990 teve um reconhecimento importante da sua necessidade. Corrêa (2003) é mais abrangente já que especifica os direitos adquiridos como, por exemplo, a Declaração dos Direitos da Criança, o Referencial Curricular Nacional para a Educação Infantil, de 1998 e o Estatuto da Criança e do Adolescente - ECA (lei no 8.069 de 1990).

Nota-se que houve um avanço significativo da expansão do ensino para crianças com a criação de creches e pré-escolas, e, também, a importância do valor social e educativo nessa fase, mesmo ainda havendo divergências sobre o que deveria ser ensinado na educação infantil bem como sobre os meios de realização (SCHLICKMAN, 2002). O Referencial Curricular Nacional (1998) nos redimensiona a pensar que o aluno com idade de zero a seis anos vive e experimenta atividades que as levam a ter prazer em praticar, nas instituições de ensino, o exercício e formação da cidadania com base nos princípios:

Respeito à dignidade e aos direitos das crianças, consideradas nas suas diferenças individuais, sociais, econômicas, culturais, étnicas, religiosas, 
etc. O direito das crianças a brincar, como forma particular de expressão, pensamentos, interação e comunicação infantil; $O$ acesso das crianças aos bens socioculturais disponíveis, ampliando o desenvolvimento das capacidades relativas à expressão, à comunicação, à interação social, ao pensamento, à ética e à estética; A socialização das crianças por meio de sua participação e inserção nas mais diversificadas práticas sociais, discriminação de espécie algumas; $O$ atendimento aos cuidados essenciais associados à sobrevivência e ao desenvolvimento de sua identidade (BRASIL, 1998, p.13).

Uma das principais funções das escolas é desenvolver as habilidades de seus alunos para que sejam capazes de viver em sociedade, respeitando, portanto, as regras e tendo um bom comportamento social na relação com seus amigos, professores e autoridades escolares, tratando todos com respeito e convivendo com as diferenças. Sendo o foco da aprendizagem, o crescimento e desenvolvimento da criança, a Educação Infantil é uma fase muito importante. Nesse sentido, este estudo parte do princípio de que a primeira etapa da educação se manifesta até os seis anos da vida do aluno-aprendiz. Devido à tal circunstância, a Educação Infantil possui alguns objetivos que compreendem competências e habilidades diversas que precisam ser exploradas na criança até os seis anos de idade a partir de atividades diversas, sobretudo lúdicas, como defende esta pesquisa.

- desenvolver uma imagem positiva de si, atuando de forma cada vez mais independente, com confiança em suas capacidades e percepção de suas limitações;

- descobrir e conhecer progressivamente seu próprio corpo, suas potencialidades e seus limites, desenvolvendo e valorizando hábitos de cuidado com a própria saúde e bem-estar;

- estabelecer vínculos afetivos e de troca com adultos e crianças, fortalecendo sua autoestima e ampliando 
gradativamente suas possibilidades de comunicação e interação social;

- estabelecer e ampliar cada vez mais as relações sociais, aprendendo aos poucos a articular seus interesses e pontos de vista com os demais, respeitando a diversidade e desenvolvendo atitudes de ajuda e colaboração;

- observar e explorar o ambiente com atitude de curiosidade, percebendo-se cada vez mais como integrante, dependente e agente transformador do meio ambiente $\mathrm{e}$ valorizando atitudes que contribuam para sua conservação;

- brincar, expressando emoções, sentimentos, pensamentos, desejos e necessidades;

- utilizar as diferentes linguagens (corporal, musical, plástica, oral e escrita) ajustadas às diferentes intenções e situações de comunicação, de forma a compreender e ser compreendido, expressar suas ideias, sentimentos, necessidades e desejos e avançar no seu processo de construção de significados, enriquecendo cada vez mais sua capacidade expressiva;

- conhecer algumas manifestações culturais, demonstrando atitudes de interesse, respeito e participação frente a elas e valorizando a diversidade (BRASIL, 1998, p. 63).

O professor, então, precisa se atualizar e inovar o exercício docente, pois, dessa forma, as competências e habilidades diversas serão devidamente exploradas ao longo desses seis anos que compreendem a educação infantil de forma plena e eficaz. Assim, deve, de forma contínua, procurar melhorar cada detalhe de seus métodos educacionais em busca de ótimos resultados para a formação e desenvolvimento da criança, pois esse é o papel do ensino que é ministrado na educação fundamental e infantil. 


\subsection{O USO DO LÚDICO NO DIA-A-DIA DOCENTE}

O desenvolvimento infantil tem se modificado e se tornado mais valorizado com o decorrer do tempo na educação escolar. Kishimoto (2001, p. 28), em seu estudo, elucida que os jogos influenciam diretamente no "desenvolvimento da imaginação, da representação simbólica, da cognição, dos sentimentos, do prazer, das relações, da convivência, da criatividade, do movimento e da autoimagem dos indivíduos". Nesse sentido, cabe, ao docente, o trabalho com o lúdico nas séries iniciais para que a criança se sinta inclinada a aprender com base nas novas estratégia. O lúdico desperta, nas crianças, a felicidade necessária para que se sinta motivada a desenvolver uma dada atividade. O professor deve sempre refletir sobre suas práticas a fim de conseguir incluir o lúdico ao conteúdo programático proposto, já que como elucida Santo (2008, p. 52):

O papel do professor durante os jogos deve ser o de provocar e desafiar a participação coletiva na busca de encaminhamentos e resolução dos problemas, pois é através do jogo que podemos despertar e incentivar a criança para o espírito de companheirismo de cooperação gradativamente, ela vai assumindo e compreendendo sua posição como um membro de um grupo social.

A aprendizagem para ser efetiva dependerá da motivação empregada em aula assim como das necessidades e interesses das crianças. Conforme o Referencial Curricular Nacional de Educação Infantil (RCNEI, 1998, p. 29):

O brincar apresenta-se por meio de várias categorias de experiências que são diferenciadas pelo uso do material ou dos recursos predominantemente implicados. Essas categorias incluem: o movimento e as mudanças da percepção resultantes essencialmente da mobilidade física das crianças; a relação com os objetos e suas propriedades físicas assim como a combinação e associação entre eles; a linguagem oral e gestual que oferecem vários níveis de organização a serem utilizados para brincar; os conteúdos sociais, como papéis, situações, valores e 
atitudes que se referem à forma como o universo social se constrói; e, finalmente, os limites definidos pelas regras, constituindo-se em um recurso fundamental para brincar. Estas categorias de experiências podem ser agrupadas em três modalidades básicas, quais sejam brincar de faz-de-conta ou com papéis, considerada como atividade fundamental da qual se originam todas as outras; brincar com materiais de construção e brincar com regras. Conforme as considerações apontadas no documento citado anteriormente, as brincadeiras de fazde-conta, os jogos de construção e aqueles que possuem regras, como os jogos de sociedade (também chamados de jogos de tabuleiro), jogos tradicionais, didáticos, corporais etc., propiciam a ampliação dos conhecimentos infantis por meio da atividade lúdica (BRASIL, 1998, p. 29).

As atividades lúdicas favorecem a adesão a um ambiente escolar mais harmonioso, afetando, igualmente, o fazer pedagógico e a aprendizagem, e, assim, o ato de aprender se torna mais atrativo, e, principalmente, prazeroso.

\section{CONSIDERAÇÕES FINAIS}

Com este artigo foi possível concluir que o lúdico pode auxiliar, principalmente, nos processos que englobam técnicas que contemplam as técnicas de aprender e letrar na primeira base da educação básica. Notou-se, ainda, que exercícios lúdicos estimulam e motivam a criança-aprendiz a pensar. Isso é bastante significativo, pois ela se torna capaz de se envolver, de forma mais ativa, com o seu processo de aprendizagem, estando mais aberta a novas abordagens. Amplia, então, quando possui uma mentalidade mais aberta, o seu raciocínio lógico, as suas habilidades, o seu pensamento e a sua criatividade. $\mathrm{O}$ ato de usar o brincar para se comunicar $\mathrm{e}$ aprender, ao mesmo tempo, é fundamental para que as várias dimensões que dão forma à essa criança possam ser desenvolvidas. 


\section{REFERÊNCIAS}

BARBOSA, R. F. M. Influências brincantes: um estudo sobre a cultura lúdica infantil e o desenho animado. 2011. 141 f. Dissertação (Mestrado em Educação) Instituto de Educação, Universidade Federal de Mato Grosso, Cuiabá, 2011.

BARRETO, S. de. Jesus. Psicomotricidade: Educação e Reeducação. Blumenau: Odorizzi, 2008.

BENJAMIN, W. Reflexões sobre a criança, o brinquedo e a educação. 2ª . ed. São Paulo: Duas Cidades; Editora 34, 2009.

BRASIL. Ministério da Educação e do Desporto. Secretaria de Educação Fundamental. Referencial curricular nacional para a educação infantil/Ministério da Educação e do Desporto, Secretaria de Educação Fundamental. Brasília: MEC/SEF, 1998.

BROUGERE, G. Brinquedo e cultura. 2ª . ed. São Paulo: Cortez, 2001.

CAVAlCANTE, M. A. da. S.; FREITAS, M. L. Q (orgs). 0 ensino da língua portuguesa nas séries iniciais: eventos e práticas de letramento. Maceió, EDUFAL, 2008.

CHATEAU, J. O jogo e a criança. São Paulo: Summus, 2007.

CORREA, B. C. Considerações sobre qualidade na educação infantil. Cadernos de Pesquisa, n. 119, p. 85-112, 2003.

FERREIRO, E. Uma reflexão sobre a língua oral e a aprendizagem da língua escrita. Revista Pátio, Ano VIII, n. 29, p. 8-12, 2004.

GROSCH, M. S.; MELZ, R. N. Educação Infantil: um novo olhar. Dynamis (Blumenau), v. 11, n. jan/mar, p. 48-53, 2003. 
HUIZINGA, J. Homo Luddens: o jogo como elemento da cultura. São Paulo, Perspectiva, 1980.

HUIZINGA, J. Homo Ludens. 8a․ ed. São Paulo: Perspectiva, 2014.

KSHIMOTO, T. M. O jogo na educação infantil. São Paulo: Pioneira, 2001.

LEITE, S. A. (Org.). Alfabetização e letramento: contribuições para as práticas pedagógicas. Campinas: Komedi, Arte Escrita, 2001.

RIBEIRO, V. M. (Org.). Letramento no Brasil: reflexões a partir do INAF 2001. São Paulo: Global, 2003.

SCHLICKMAM, J. N. Educação infantil: fios e desafios. Revista Poiésis, v. 4, ㄲo 7/8, p. 13-25, jan./dez. 2002.

SOARES, M. Letramento e alfabetização: as muitas facetas. Revista brasileira de educação, n. 25, p. 5-17, 2004.

TFOUNI, L. V. Letramento e alfabetização. São Paulo: Cortez, 2015.

VYGOTSKY, L. S. A formação social da mente. 6ª ed. São Paulo: Martins Fontes, 1998.

Enviado: Março, 2020.

Aprovado: Março, 2020. 